\title{
Studies on the Genetics of Biotin-Transducing, Defective Variants of Bacteriophage $\lambda^{1}$
}

\author{
GARY KAYAJANIAN² \\ Department of Biology, University of Rochester, Rochester, New York 14627, and Department of Human \\ Genetics, University of Michigan, Ann Arbor, Michigan 48104
}

Accepted May 23,1968

\begin{abstract}
A collection of $\lambda$ bio transducing particles were isolated and the phage and bacterial extent of their genomes characterized. $\lambda$ bio transducing phages transduce variable amounts of bacterial genome, and have densities that differ from one independent HFT to another. Some of the transducing particles are able to form plaques $(\lambda \mathrm{pb})$, others are not $(\lambda \mathrm{db})$; the $\lambda d \mathrm{dbs}$ have phage defects of various extents. The nature of the $\lambda \mathrm{db}$ particles conforms to the structural predictions of the Campbell model. Some of the properties of $\lambda$ bio particles and $(\lambda \mathrm{db})$ lysogens are described and discussed.
\end{abstract}

\section{INTRODUCTION}

Phage $\lambda$ acts as a transducing agent for host markers located very close to its attachment site: for a cluster of galactose genes (Morse et al., 1956a, b; Campbell, 1959), an aromatic marker (Wallace and Pittard, 1967), and a series of loci responsible for the synthesis of biotin (Rothman, 1965; del Campillo-Campbell et al., 1967).

We undertook to isolate and characterize a number of biotin transducing variants of $\lambda$ for a number of reasons. First, to test the validity of the Campbell model, which delimits in a very precise manner the genetic and physical quality of the genomes of transducing $\lambda$ variants. Some of these predictions are explicit: namely, the DNA in transducing particles should represent a contiguous block of genetic and physical material drawn from a lysogenic bacterial chromosome. Implicit in the model is the requirement of the vegetative ends in all genomes able to go through a lysogenic cycle. Second, one might expect not to find

${ }^{1}$ Supported by United States Public Health Service Grants E-2862 and PO 1 GM15419-01.

${ }^{2}$ Present address: Department of Biochemistry, Stanford University School of Medicine, Palo Alto, California 94304. certain classes of transducing genomes that could be formed à la Campbell but would be unable to survive as single defective lysogens for reasons of physiology. Genetic material in the arm of $\lambda$ that might be deleted in defective biotin transducing genomes would be concerned with functions of $\lambda$ occurring early in the cellular development of phage $\lambda . \lambda c_{1}$ genomes are unable to establish a stable relation with their host, but would $\lambda \mathrm{db}$ genomes missing $c_{\mathrm{I}}$ and (according to Campbell) other early regions of $\lambda$ be able to form a stable lysogenic complex with its host? Third, we were interested in ordering a large number of biotin mutants of Escherichia coli (del Campillo-Campbell et al., 1967) and a large number of $\lambda$ mutants for which Campbellian $\lambda$ bio genomes would be valuable.

\section{MATFRIATS AND MFTHODS}

\section{Media}

Synthetic medium with $1 \%$ glucose, $0.4 \%$ 2,3,5-triphenyltetrazolium chloride, and supplements of leucine and thiamine served as our biotin transduction medium (Kayajanian and Campbell, 1966). Cells not requiring exogenous biotin for growth (bio $\left.{ }^{+}\right)$ grow to form dark red colonies on a white 
TABLE 1

Bacterial Strains

\begin{tabular}{|c|c|c|}
\hline Strain & Properties $^{a}$ & Function \\
\hline C600 & $\mathrm{gal}^{+}, \mathrm{bio}^{+}, \mathrm{leu}^{-}, \mathrm{thi}^{-}, \mathrm{pm}^{+}$ & $\lambda$ assay \\
\hline $\mathrm{C} 600(\lambda)$ & $\mathrm{gal}^{+}, \mathrm{bio}^{+}, \mathrm{leu}^{-}, \mathrm{thi}^{-}$, lysogenic & $\begin{array}{l}\text { Source of gal and bio LFT } \\
\text { particles }\end{array}$ \\
\hline W33.50 & $\begin{array}{l}\mathrm{gal}^{-} \text {(kinaseless and transferaseless) } \mathrm{bio}^{+} \\
\mathrm{pm}^{-}\end{array}$ & $\begin{array}{l}\text { Recipient in gal transduction } \\
\text { sus assay }\end{array}$ \\
\hline W3805 & $\mathrm{gal}^{-}$(epimeraseless) bio ${ }^{+}, \mathrm{pm}^{-}$ & " \\
\hline W602 & $\begin{array}{l}\text { gal- (transferaseless), bio }^{-}, \mathrm{pm}^{-} \\
\text {designated bio } \\
-0\end{array}$ & $\begin{array}{l}\text { Recipient in bio and gal trans- } \\
\text { duction }\end{array}$ \\
\hline $\begin{array}{l}A C 2,3,4,12 \\
\quad 17,18,19,23, \\
24\end{array}$ & $\begin{array}{l}\mathrm{gal}^{+}, \mathrm{pm}^{-} \text {, bio nitrosoguanidine treated de- } \\
\text { rivatives of a gal } \text { bio }^{+} \text {segregant of } E \text {. } \\
\text { coli strain } 15-68 \text { (Campbell, 1965; del } \\
\text { Campillo-Campbell, Kayajanian, Camp- } \\
\text { bell and Adhya, 1967), designated bio- } 2 \text {, } \\
\text { 3, 4, etc. }\end{array}$ & Recipient in bio transduction \\
\hline
\end{tabular}

"Notation: $\mathrm{gal}^{-}=$unable to utilize galactose as a carbon source; bio- $=$requires biotin for growth; leu ${ }^{-}=$requires leucine for growth; thi $\mathrm{i}^{-}=$requires thiamine for growth; $\mathrm{pm}^{+}=$permissive host for sus mutants; $\mathrm{pm}^{-}=$nonpermissive host for sus mutants.

TABLE 2

Pilage Strains

\begin{tabular}{|c|c|}
\hline Strains & Function \\
\hline$\lambda . W 3350$ & $\begin{array}{l}\text { Helper phage for gal transduc- } \\
\text { tions on } W 3350\end{array}$ \\
\hline$\lambda$. bio-0 & Helper phage for bio and gal \\
\hline$\lambda c_{71}$ & $\begin{array}{l}\text { transductions on bio }-0 \lambda c_{I} \\
\text { with } \lambda \text { 's density }\end{array}$ \\
\hline$\lambda e_{\mathrm{r}-47} s u s 8$ & $\begin{array}{l}\text { Recombinant between } \lambda c_{\mathrm{I}-47} \\
\text { and sus } 8 \text {, for marker rescue }\end{array}$ \\
\hline$\lambda c_{n-68} s u s 8$ & $\begin{array}{l}\text { Recombinant between } \lambda c_{I I-68^{a}} \\
\text { and sus } 8 \text {, for marker rescue }\end{array}$ \\
\hline$\lambda c_{\mathrm{I}+2} s u s 29^{a}$ & For marker rescue \\
\hline$\lambda c_{\text {Itus1 }} s u s 29^{a}$ & For marker rescue \\
\hline$\lambda c_{1 \mathrm{t}} s u s 29^{a}$ & For marker reseue \\
\hline$\lambda c_{1+u{ }_{46}} s u s 29^{a}$ & For marker rescue \\
\hline$\lambda c_{\text {It } 150} s u s 29^{a}$ & For marker rescue \\
\hline$\lambda c b 2$ & $\begin{array}{l}\text { A clear plaque density mulant } \\
\text { with an estimated DNA con- } \\
\text { tent of } 86.5 \% \text { of our } \lambda \text { 's }\end{array}$ \\
\hline$\lambda d g_{4}$ & $\begin{array}{c}\text { A density marker } \lambda d g \text { (Kaya- } \\
\text { janian and Campbell, 1966) }\end{array}$ \\
\hline$\lambda \mathrm{dg}_{1}^{+}$ & $\begin{array}{l}\text { A } \text { gal }^{+} \text {transducing phage, } \\
\text { missing phage markers from } \\
\text { sus A to sus J }\end{array}$ \\
\hline $\begin{array}{l}\text { Asus } \mathbf{A}_{11}, \mathrm{~B}_{10} \\
\mathbf{J}_{6}, \mathrm{~N}_{7}, \mathrm{~N}_{53} \\
\mathrm{O}_{8}, \mathrm{O}_{29}, \mathrm{O}_{125} \\
\mathrm{P}_{33}, \mathrm{P}_{72}, \mathrm{P}_{116} \\
\mathrm{Q}_{21}, \mathrm{Q}_{73}, \mathrm{Q}_{117} \\
\mathrm{R}_{5}, \mathrm{R}_{16}, \mathrm{R}_{54} \\
\mathbf{R}_{60}\end{array}$ & For marker reseue \\
\hline
\end{tabular}

"Kindly sent by Dr. M. Lieb. background of a biotin-requiring ( $\mathrm{bio}^{-}$) strain on this medium. The medium used to detect biotin segregation was Trisbuffered synthetic medium with $0.4 \%$ glucose, $7 \times 10^{-4} \mathrm{M} \mathrm{NaHCO}{ }_{3}, 1 \mathrm{mg} /$ liter thiamine, $20 \mathrm{mg} /$ liter leucine, about $5 \times$ $10^{-2} \mu \mathrm{g} /$ liter biotin, and eosin $\mathrm{Y}$ and methylene blue as in EMB agar. On this medium bio $^{+}$colonies are large with prominent dark centers and thick white rims; bio- colonies are smaller and are either entirely dark or have a very thin white rim surrounding the dark center. Bio variable colonies are of two types: one looks like bio $^{+}$colonies; the other is highly sectored. Segregation for the gal and bio markers can be observed simultaneously on the segregation medium if galactose replaces glucose in the recipe. The composition of soft, $1 \%$ and $2 \%$ tryptone agar and broth and huffer has been described previously (Kayajanian and Campbell, 1966).

\section{Methods}

The bacterial and phage strains used in our experiments are listed in Tables 1 and 2. LFT biotin transducing activity was assayed on bio 0 cells (with helper phage), which were plated on minimal medium with glucose. The dark red transductants were streaked on the segregation medium, and a well isolated $\mathrm{bio}^{+}$colony was streaked 
again. If this second plate contained at least one bio ${ }^{-}$or sectored colony from among 300 well isolated colonies, the transduced cell was classified as heterogenotic (het); if not, it was designated a stable $\mathrm{bio}^{+}$ transductant.

$\lambda$ bio particles werc characterized as plaque-forming $(\lambda \mathrm{pb})$ if the lysogenic centers of individual plaques made from an HHT lysate consisted of bio $^{+}$transductants. Induction of these lysogens produces particles almost all of which transduce the lysogenic cells in the center of plaques they make on bio 0 . In practice $\lambda$ pb plaques are distinguished from $\lambda$ plaques by their pink color on a bio host on transduction medium; $\lambda$ plaques do not have this hue. Isolation of defective lysogens among biocells transduced by other HFT lysates allowed the classification of non-plaqueforming, bio transducing particles $(\lambda \mathrm{db})$. We isolated $\lambda \mathrm{db}$ lysogens after the procedures of Campbell (1959) for $\lambda$ dg lysogens. These defective lysogens were picked as $\mathrm{bio}^{+}$colonies which when induced and spotted with the mutant phage $\lambda$ susJ6, on a nonpermissive $\left(\mathrm{pm}^{-}\right)$strain produced a region of lysis. Neither the phage $\lambda$ susJ 6 nor the induced lysogen spotted alone on a $\mathrm{pm}^{-}$background produced this lysis. The phage content of a $\lambda \mathrm{db}$ genome was determined by sus ${ }^{+}$marker rescue from the defective lysogen. The presence of superinfection immunity in the lysogen was assayed by plating dilute $\lambda$ lysates on backgrounds of the defective lysogens. When appropriate, the presence or absence of some $\mathrm{c}_{\mathrm{I}}{ }^{+}$and $\mathrm{cII}^{+}$alleles in the $\lambda \mathrm{db}$ genomes was assayed by infecting the induced $\lambda \mathrm{db}$ lysogen with $\lambda c_{I} s u s 0$ or $\lambda c_{I I} s u s 0$ and plating the phage yield after 110 minutes on a $\mathrm{pm}^{-}$ strain. Turbid plaques on the $\mathrm{pm}^{-}$host (at $43^{\circ}$ for $c_{\text {Its }}$ mutants) indicate the presence in the $\lambda \mathrm{db}$ genome of the $\mathrm{c}^{+}$allele of the infecting phage mutant. The identity of bio ${ }^{+}$ alleles present in each $\lambda$ bio isolate was determined by spotting about $0.05 \mathrm{ml}$ of an HFT lysate on lawns of the different biomutants spread on the transduction medium (del Campillo-Campbell et al., 1967).

Phage lysates were made by the induction of lysogens or by the infection of sensitive cells in equal volumes of broth and buffer (Kayajanian and Campbell, 1966).

Density gradient experiments were performed as described in Kayajanian and Campbell (1966).

\section{RESULTS}

Of 420 bio $^{+}$transductants picked from an LFT lysate, 72 or $17.2 \%$ were hets. The hets were the sole source of our $\mathrm{HF}^{\prime} \mathrm{I}$ biotin transducing lysates. No $(0 / 39)$ nonsegregating, $\lambda$ lysogenic biotin transductants produced a lysate with a biotin transducing activity greater than $5 \times 10^{3} / \mathrm{ml}$. Of nearly 100 hets examined, all but one had transducing titers greater than $6 \times 10^{4} / \mathrm{ml}$. Most of the HFT titers were about $10^{6}$ to $10^{7}$ transductants $/ \mathrm{ml}$.

Our HFT lysates had disappointingly low transducing titers. We were concerned that somehow our assay for transducing particles was not very efficient. It is possible that the presence of some phage function(s) missing in $\lambda$ bio might be provided by normal $\lambda$. But the presence of $\lambda$ as helper does not markedly alter the efficiency of transduction by $\lambda$ bio phage particles (Table 3).

Yet the measure of transduction frequency is not equivalent to the number of transducing particles. A lysate made by the induction of the single lysogen bio $0(\lambda \mathrm{pb}$ M72-3) yields a transducing activity on bio $^{-0}$ of $1.3 \times 10^{6} / \mathrm{ml}$ and a plaque-forming activity on the same host of $1.6 \times 10^{8}$ (the lysogenic centers of nearly all of the $\lambda \mathrm{pb}$ plaques contain bio $^{+}$cells). So the efficiency of transduction is $7.8 \times 10^{-3}$ of the plaqueforming activity of $\lambda$ pbM72-3.

For $\lambda d b$ 's, ultraviolet (UV) absorption constitutes an independent assay of the

TABLE 3

Effect of $\lambda$ Helper on Transduction Frequency of Three $\lambda$ bio's

\begin{tabular}{cccc}
\hline Abio & $\begin{array}{c}\text { Phage } \\
\text { end point }\end{array}$ & \multicolumn{2}{c}{ Frequency of transduction } \\
\cline { 3 - 4 } & & No helper & Moi of helper \\
\hline- & - & - & 2.3 \\
$\mathrm{M} 7-20$ & $\lambda \mathrm{pb}$ & $3.8 \times 10^{5}$ & $1.2 \times 10^{5}$ \\
$\mathrm{M} 3-29$ & $\mathrm{~N} / \mathrm{c}$ & $2.2 \times 10^{5}$ & $1.8 \times 10^{5}$ \\
$\mathrm{M} 29-7$ & $\mathrm{O} / \mathrm{P}$ & $6.5 \times 10^{4}$ & $2.3 \times 10^{5}$ \\
\hline
\end{tabular}


GENETICS OF $\lambda \mathrm{dbs}$

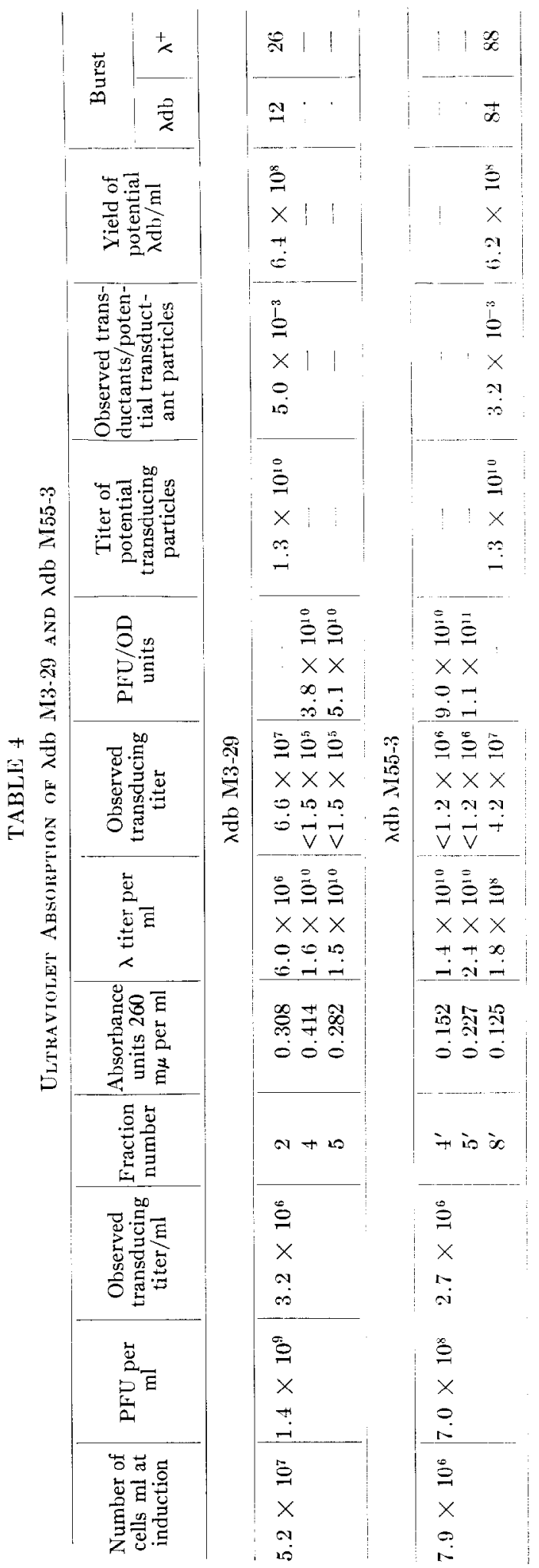


number of transducing particles (Smith, 1968). Phage induced from bio -0 ( $\lambda \mathrm{db} \mathrm{M} 3$ 29) $(\lambda)$ and from bio $-0(\lambda \mathrm{db}$ M55-3) $(\lambda)$ were concentrated by pelleting, treated with RNase and DNase, and fractionated in a $\mathrm{CsCl}$ density gradient. The UV absorption at $260 \mathrm{~m} \mu$ of three fractions from these gradients, two primarily rich in $\lambda$, the other predomniantly $\lambda \mathrm{db}$, was measured. These data (Table 4), corrected for the relative amounts of DNA in the transducing the plaque-forming phage [as judged by phage density measurements (Table 7)] and for the UV-absorbing residue from the original lysates, rcveal approximatcly the relativo efficiency of transduction by $\lambda \mathrm{db}$ M3-29 and M55-3 as $5.0 \times 10^{-3}\left(6.6 \times 10^{7} / 1.3 \times 10^{10}\right)$ and $3.2 \times 10^{-3}\left(4.2 \times 10^{7} / 1.3 \times 10^{10}\right)$.

The plaque-forming and transducing activity in the lysate harvested from the induction of bio-0 $\left(\lambda \mathrm{db}\right.$ M3-29) (at $5.2 \times 10^{7}$ cells $/ \mathrm{ml}$ ) were, respectively, $1.4 \times 10^{9} / \mathrm{ml}$ and $3.2 \times 10^{6} / \mathrm{ml}$. So the yield of $\lambda \mathrm{db}$ (M3-29) particles in this lysate is $6.4 \times 10^{8}$ $\left(3.2 \times 10^{6} / 5.0 \times 10^{-3}\right)$. If the plaqueforming activity is a good measure of the number of $\lambda$ particles, the yield of transducing particles is about one-half the number of $\lambda$ particles. The approximate burst size of $\lambda$ particles per induced cell is $26\left(1.4 \times 10^{9}\right.$ $\mathrm{PFU} / \mathrm{ml} / 5.2 \times 10^{7}$ cells $/ \mathrm{ml}$ ); the $\lambda \mathrm{db}$ burst is about 12 . In a second experiment, the induction of bio-0 ( $\lambda \mathrm{db}$ M55-3) $(\lambda)$ (at $7.9 \times$ $10^{6}$ cells $/ \mathrm{ml}$ ) yielded a lysate with a plaqueforming titer of $7.0 \times 10^{8}$ and a transducing titer of $2.7 \times 10^{6} / \mathrm{ml}$. The $\lambda$ burst then is 88 $\left(7.0 \times 10^{8} \mathrm{PFU} / \mathrm{ml} / 7.9 \times 10^{6}\right.$ cells $\left./ \mathrm{ml}\right)$. The $\lambda \mathrm{db}$ burst is nearly at the $\lambda$ level (84). We do not find transducing particles in induction of $\lambda \mathrm{db}$ defective lysogens. So it appears that $\lambda \mathrm{db}$ genomes multiply with $\lambda$ help in the induced double lysogen.

\section{Genetic Extent of $\lambda d b$ Genomes}

We assayed for the presence or absence of certain phage and bacterial markers in the genomes of a number of our $\lambda$ bio transducing phages. For some of our assays, we made defective lysogens from bio transducing HFT lysates. The ability of defective lysogens to contribute certain sus ${ }^{+}$or $\mathrm{c}^{+}$alleles but not others, revealed which sus ${ }^{+}$or $\mathrm{c}^{+}$markers were carried by each $\lambda \mathrm{db}$ genome. The ability or inability of phage $\lambda$ to plate on defective lysogens indicated the absence or presence in the $\lambda \mathrm{db}$ genome of an intact and functioning $c_{I}$ region. The ability or inability of $\lambda$ bio lysates to transduce biomutants other than the one on which they were originally selected, revealed the extent of the bacterial chromosome carried inside the transducing phages. The extent of a number of $\lambda$ bio genomes is described in Table 5. As in the case of $\lambda \mathrm{dg}$, each $\lambda$ bio genome represents a contiguous block of phage and bacterial genes from a $\lambda$ lysogenic bacterial chromosome. Loss of the bio ${ }^{+}$ phenotype from $\lambda \mathrm{db}$ lysogens, presumably by segregation, was nearly always accompanied by loss of the phage markers associated with it in the transducing genome.

The variety of phage and bacterial markers in the $\lambda$ bio genomes permits us to map the right arm of the $\lambda$ chromosome and

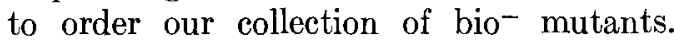
Three of the $26 \lambda \mathrm{db}$ genomes (R30h-2a, M38-5, E5a-20) are clearly broken within the phage cistrons $\mathrm{O}$ and $\mathrm{P}$ and can be used to order the various sus $\mathrm{O}$ and $\mathrm{P}$ mutants:

$$
\begin{aligned}
N_{7,53}-O_{8,29} & -O_{125} \\
& -P_{72}-P_{3}-P_{116}-Q, R
\end{aligned}
$$

The pattern of transduction of the $\lambda$ bio lysates on different bio- mutants, orders the bacterial mutants into seven classes:

$$
\begin{aligned}
\lambda-0,4,24- & 2,17 \\
& -12-3-23-18-19
\end{aligned}
$$

(del Campillo-Campbell et al., 1967).

Those $\lambda \mathrm{db}$ genomes which gave sus ${ }^{+}$ marker rescue for susO, but not for sus $\mathrm{N}$ were also tested for immunity against superinfection by $\lambda$ and for $\mathrm{c}_{\mathbf{I}}{ }^{+}$and $\mathrm{crI}^{+}$marker rescue with $\mathrm{c}_{\mathrm{I}} s u s \mathrm{O}$ and $\mathrm{c}_{\mathrm{II}}$ susO (Table 6). Of eleven $\lambda \mathrm{db}$ genomes examined, one (R24-2) gives marker rescue for none of the clear mutants tested, is not immune to superinfection by phage $\lambda$, and thus seems to be broken either within the $c_{I I}$ cistron or between $c_{I I}$ and the $O$ cistron. Four (M3-29, R24-5, R3h-1, M16-3) give marker rescue for all of the $c_{I}$ and $c_{I I}$ mutants tested, and are immune to superinfection, and thus seem 
TABLE 5

Phage and Bacterial knd Points of Some $\lambda$ bio Transducing Genomes ${ }^{a}$

\begin{tabular}{|c|c|c|c|c|c|c|c|c|c|c|c|c|c|c|c|c|c|c|c|}
\hline hi & $N_{7,63}$ & $\mathrm{i}^{\lambda}$ & $\mathrm{CI}_{47}$ & 曾 & CIIng & $\mathrm{O}_{8.29}$ & $O_{125}$ & $P_{72}$ & $P_{3}$ & $P_{118}$ & $\begin{array}{l}\mathrm{Q}_{21,3.1177} \\
\mathrm{R}_{6,66.64,60}\end{array}$ & $\begin{array}{c}A_{11} \\
J_{6}\end{array}$ & $\begin{array}{l}\mathrm{bio}^{-} \\
0,4 \\
24\end{array}$ & $\begin{array}{l}\mathrm{bio}^{-} \\
2,17\end{array}$ & $\begin{array}{c}\text { bio }^{-} \\
12\end{array}$ & $\begin{array}{c}\mathrm{bio}^{-} \\
3\end{array}$ & $\begin{array}{l}\text { bio } \\
2.3\end{array}$ & $\begin{array}{c}\text { bio }^{-1} \\
\text { is }^{2}\end{array}$ & $\begin{array}{c}\text { bio- } \\
19\end{array}$ \\
\hline M108-1 & + & + & $\mathrm{N}$ & $\mathrm{N}$ & $\mathrm{N}$ & + & + & + & + & + & + & + & + & + & + & + & + & t & - \\
\hline$M 72-3$ & + & t & $N$ & $N$ & $\mathrm{~N}$ & + & + & + & 1 & + & + & + & + & + & + & + & + & + & 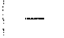 \\
\hline M66-1 & + & + & $\mathrm{N}$ & $\mathrm{N}$ & $\mathrm{N}$ & + & + & + & + & + & + & + & + & + & + & + & + & + & - \\
\hline$M_{47-1}$ & + & + & $N$ & $N$ & $\mathrm{~N}$ & + & + & + & 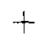 & + & + & + & + & + & + & + & + & + & - \\
\hline M38-3 & + & + & $\mathrm{N}$ & $\mathrm{N}$ & $\mathrm{N}$ & + & + & + & + & + & + & + & + & + & + & + & + & + & - \\
\hline M22-5 & + & + & $\mathrm{N}$ & $\mathrm{N}$ & $\mathrm{N}$ & + & + & + & + & + & + & + & + & $t$ & + & + & + & + & - \\
\hline M18-4 & + & + & $\mathrm{N}$ & $\mathrm{N}$ & $\mathrm{N}$ & + & + & + & + & + & + & + & + & + & + & $t$ & + & + & - \\
\hline$\lambda$ & + & + & $N$ & $\mathrm{~N}$ & $\mathrm{~N}$ & + & + & $t$ & + & + & + & + & $t$ & + & + & + & + & + & - \\
\hline MI & + & + & $N$ & $\mathrm{~N}$ & $\mathrm{~N}$ & + & + & + & + & + & t & + & + & + & + & + & + & + & - \\
\hline & + & + & $N$ & $\mathrm{~N}$ & $\mathrm{~N}$ & + & + & + & t & + & + & + & + & + & + & + & + & - & - \\
\hline$M 7-20$ & + & + & $N$ & 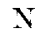 & $\mathrm{N}$ & + & + & + & + & + & + & + & + & + & + & + & + & - & - \\
\hline$[5-5$ & + & + & $\mathrm{N}$ & $\mathrm{N}$ & $\mathrm{N}$ & + & + & + & + & +1 & + & + & $\mathrm{N}$ & $N$ & $N$ & $N$ & $\mathrm{~N}$ & $\mathrm{~N}$ & $\mathrm{~N}$ \\
\hline M $3-29$ & - & + & + & + & + & + & + & + & + & + & + & + & + & + & + & + & + & + & + \\
\hline $\mathrm{R} 24-5^{b}$ & - & + & + & + & + & + & + & + & + & + & + & + & + & + & + & + & + & + & + \\
\hline R $3 \mathrm{~h}-1^{b}$ & - & + & t & + & + & + & + & + & t & + & t & + & + & + & + & + & + & + & + \\
\hline ML16-: & - & + & + & + & + & + & + & + & + & + & t & + & + & + & + & - & - & - & - \\
\hline XI30- & - & - & - & + & + & + & + & + & + & + & + & + & + & t & $t$ & + & + & + & - \\
\hline $\mathrm{I}$ & - & - & - & + & + & + & + & + & + & + & + & + & + & + & + & + & + & + & - \\
\hline MI38- & - & - & - & + & + & + & + & + & + & + & $t$ & t & 1 & 1 & 1 & 1 & t & $\ldots$ & \\
\hline $\mathrm{M} 42-2$ & - & - & - & + & + & + & + & + & + & + & + & + & + & + & + & + & - & - & - \\
\hline $\mathrm{X}[40-3$ & - & - & - & + & + & + & + & + & + & + & + & $1+$ & + & + & - & - & - & - & - \\
\hline$\lambda$ & - & - & - & + & + & + & + & + & $T$ & + & + & + & + & - & - & - & - & -- & - \\
\hline $\mathrm{R} 24-2$ & - & - & - & - & - & + & + & + & + & $1+$ & + & + & t & t & + & $t$ & + & + & t \\
\hline$\lambda\left[20_{-5}^{-5}\right.$ & - & $\mathrm{N}$ & $N$ & $\mathrm{~N}$ & $\mathrm{~N}$ & + & + & + & + & + & + & + & + & + & + & + & + & + & + \\
\hline $\mathbf{R}$ & - & $\mathrm{N}$ & I & $\mathrm{x}$ & $\mathrm{N}$ & - & + & + & + & + & 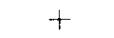 & + & + & + & + & t & + & + & + \\
\hline 3 & - & $\mathrm{N}$ & $\mathrm{N}$ & $\mathrm{N}$ & $\mathrm{N}$ & - & - & + & + & + & r & + & + & + & + & + & + & + & + \\
\hline $\mathrm{NL} 30-2$ & - & $\mathrm{N}$ & 1 & $\mathrm{~N}$ & $N$ & - & - & + & $\mathrm{T}$ & + & 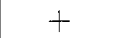 & $t$ & + & + & + & + & + & + & + \\
\hline$\lambda$ & - & - & - & - & - & - & - & + & + & + & + & + & + & + & $1+$ & + & + & + & + \\
\hline R $40 \mathrm{~h}-1 \mathrm{l}$ & - & $\mathrm{N}$ & $\mathrm{N}$ & $\mathrm{N}$ & $\mathrm{N}$ & - & - & + & + & + & + & $1+$ & + & + & + & + & + & + & t \\
\hline & - & $\mathrm{N}$ & $\mathrm{N}$ & $\mathrm{N}$ & $\mathrm{N}$ & - & - & + & + & + & 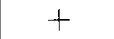 & + & + & + & + & + & + & + & + \\
\hline & - & $N$ & $N$ & $N$ & $\mathrm{~N}$ & - & - & t & + & . & + & + & + & + & + & + & + & + & - \\
\hline М36-2 & - & $N$ & $N$ & $\mathrm{~N}$ & $N$ & - & - & + & t & + & + & + & $\mathrm{N}$ & $\mathrm{N}$ & $\mathrm{N}$ & $\mathrm{N}$ & N & $N$ & $N$ \\
\hline $\mathrm{N}$ & - & $\mathrm{N}$ & $\Gamma$ & $\gamma$ & $N$ & - & - & - & + & + & + & + & + & + & + & + & + & - & - \\
\hline E.5a- & - & $\mathrm{N}$ & $\mathrm{N}$ & y & $N$ & - & - & - & - & + & + & + & + & + & + & + & + & - & - \\
\hline$\backslash 139-2$ & - & $N$ & $\mathrm{~N}$ & 1 & $\mathrm{~N}$ & - & - & - & - & - & 1 & + & + & + & + & + & + & + & t \\
\hline & - & $\mathrm{N}$ & $N$ & $\lambda$ & $\mathrm{N}$ & - & 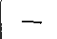 & - & - & - & + & + & + & + & + & + & + & + & + \\
\hline & - & $N$ & N & $N$ & $\mathrm{~N}$ & - & - & - & - & - & . & + & $\mathrm{N}$ & $x$ & $N$ & $N$ & $N$ & $\mathrm{~N}$ & $\mathrm{~N}$ \\
\hline $1[55-3$ & - & $\mathrm{N}$ & $\lambda$ & $\lambda$ & $\mathrm{N}$ & - & - & - & 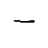 & - & - & + & + & + & + & + & + & - & - \\
\hline
\end{tabular}

a Bacterial and phage end points were determined as indicated in the Methods section. + indicates the presence of a given marker; -, the absence; $N$, not tested. The first 12 genomes listed were from $\lambda \mathrm{pb}$ particles; their ability to generate immunity was tested. The ability of $\lambda$ pbs to generate plaques on W3350 was interpreted to mean that $\operatorname{sus} \mathrm{N}^{+}, \mathrm{O}^{+}, \mathrm{P}^{+}, \mathrm{Q}^{+}, \mathrm{R}^{+}, \mathrm{A}^{+}, \mathbf{J}^{+}$were present in the phage genome. More complete data on $\mathrm{c}^{+}$marker rescue from $\lambda \mathrm{dbs}$ are given in Table 6 .

${ }^{b}$ All $\lambda d \mathrm{~b}$ genomes tested for marker rescue are in bio-0, except for these two, which are in bio, ${ }^{-3}$.

to end between the $c_{I}$ region and the $N$ cistron. One of these four excludes $\mathrm{T} 4_{\mathrm{r} \text { II }}$ mutants; the other three do not (Dove, personal communication). The remaining 6 ddbs (M30-7, M29-6, M38-1, M42-2,
M40-3, M37-1) are not immune to superinfection, give marker rescue for $c_{I I}$ and some $c_{\mathrm{I}}$ mutants, but not for other $\mathrm{c}_{1}$ mutants, and are thus broken within the $c_{I}$ region; two $\lambda d b$ genomes are broken within $\mathrm{c}_{\mathrm{I}} \mathrm{B}$; the 
TABLE 6

$c^{+}$Marker Rescue by esusO from $\lambda$ db Defective Lysogens; Proportion of Turbid sus $^{+}$to Clear sus ${ }^{+}$Plaques

\begin{tabular}{|c|c|c|c|c|c|c|c|}
\hline \multirow{2}{*}{$\begin{array}{l}\text { Defective } \\
\text { lysogen }\end{array}$} & \multicolumn{7}{|c|}{ Infecting strain } \\
\hline & $\begin{array}{l}\text { cIA47 } \\
\text { sus } 8\end{array}$ & $\mathrm{c}_{\mathrm{I}} \mathrm{At} 2$ sus 29 & $\begin{array}{c}c_{r} \mathrm{Atu} 51 \\
\text { sus } 29\end{array}$ & $\mathrm{c}_{\mathrm{l}} \mathrm{Btu} 46$ sus 29 & $\mathrm{c}_{\mathrm{I}} \mathrm{Bt} 1$ sus 29 & $\mathrm{c}_{\mathrm{I}} \mathrm{Btu} 50$ sus 29 & $c_{\text {III }} 68$ sus 8 \\
\hline R3h-1 & 0.280 & - & - & - & - & - & 4.6 \\
\hline R24-5 & 0.305 & - & - & - & - & - & 2.8 \\
\hline M3-29 & 0.094 & 0.184 & 0.286 & - & 1.038 & 0.620 & 2.8 \\
\hline M16-3 & 0.184 & - & - & - & - & - & 2.3 \\
\hline M29-6 & $<0.013$ & $<0.0026$ & $<0.0020$ & $<0.0020$ & 0.108 & 0.046 & 2.3 \\
\hline M30-7 & $<0.003$ & $<0.0030$ & $<0.0044$ & 0.267 & 0.144 & 0.447 & 2.1 \\
\hline M38-1 & $<0.002$ & $<0.0021$ & $<0.0033$ & 0.091 & 0.184 & 0.346 & 1.8 \\
\hline M43-2 & $<0.024$ & $<0.019$ & $<0.0011$ & 0.029 & 0.044 & 0.478 & 1.8 \\
\hline M37-1 & $<0.001$ & $<0.0013$ & $<0.0013$ & $<0.0030$ & $<0.0009$ & 0.127 & 1.3 \\
\hline M40-3 & $<0.005$ & $<0.0018$ & $<0.0006$ & $<0.0041$ & $<0.0017$ & 0.29 & 1.0 \\
\hline R24-2 & $<0.003$ & $<0.0009$ & $<0.0055$ & $<0.0070$ & $<0.0016$ & $<0.0032$ & $<0.04$ \\
\hline M29-7 & $<0.010$ & - & - & - & - & - & $<0.004$ \\
\hline
\end{tabular}

other four may extend into $c_{I} A$. In general the $c_{I}$ and $c_{I I}$ mutants can be ordered with respect to each other by deletion mapping $\left(c_{\text {I } 47}, c_{\text {It } 2}, c_{\text {Itu51 }}-c_{\text {It1 }}, c_{\text {Itu } 46}-c_{\text {Itu50, }}, c_{\text {II } 68}\right)$ and to a lesser degree, by differences in the proportion of turbid to clear plaques among sus ${ }^{+}$recombinants $\left(\mathrm{c}_{\mathrm{I} 47}-\mathrm{c}_{\mathrm{It2}}-\mathrm{c}_{\mathrm{Itu} 51}-\right.$ $\left.\mathbf{c}_{\text {Itu } 46}, \mathbf{c}_{\text {It1 }}-\mathrm{c}_{\mathrm{Itu} 50}-\mathbf{c}_{\mathrm{II68}}\right)$.

There is always the potential problem that independently isolated HFT lysates may have more than one kind of bio transducing particle. Let us dismiss from consideration the existence of LFT particles in HFT lysates as $\Lambda$ dler and Templeton (1963) have described them for $\lambda d g$ lysates. To perform our marker rescue experiments, defective lysogens were made from $\lambda d b$ HFT lysates. Often more than one defective lysogen were isolated from a single HFT lysate. All these lysogens contained the same block of phage genes. We determined the densities of ten different $\lambda$ bios in $\mathrm{CsCl}$. Transducing activity in each case was confined to a narrow part of the gradient in a manner which suggested a single physical transducing class of particles.

Our $\mathrm{CsCl}$ gradient measurements (Table 7) reveal that the density of one $\lambda$ bio may differ from that of another. The plaqueforming and transducing activity in pure $\lambda$ pb lysates are associated with particles of the same density. Assuming the protein content of $\lambda$ and all the $\lambda$ bio particles to be equal, the DNA contribution to the mass of bio transducing genomes (selected on bio-0) ranges from $80 \%$ to $115 \%$ that of $\lambda$ 's (Table 7). By subtracting the DNA content of $\lambda \mathrm{db} M 37-1$ from that of $\lambda \mathrm{db}$ M29-6, a minimum size of one-seventh the DNA content of $\lambda$ can be assigned to the bio region of the E. coli chromosome.

\section{Segregation of $\lambda d b$ Lysogens}

Biotin transductants were characterized as hets by their ability to segregate bio- subclones on subculturing. About one-sixth of all LFT and two-thirds of all HFT biotin transductants are hets (Table 8). Although it is possible to distinguish sectored (bio variable) clones from either $\mathrm{bio}^{+}$or bio $^{-}$ colonies on our segregation medium, hets were characterized not so much by visible sectoring of bio ${ }^{-}(\lambda$ bio $)(\lambda)$ colonies, but by bio $^{-}$subclones arising from streaking bio( $\lambda$ bio) $(\lambda)$ lysogens. Visibly sectored colonies rarely if ever were encountered in streaking bio $^{-}(\lambda$ bio) $(\lambda)$ double lysogens or most bio( $\lambda$ bio) single lysogens. However, single lysogens of the six $\lambda d b s$ whose genomes terminate within $c_{I}$ (designated $\lambda$ dbc $_{\mathbf{I}}$ ) have very different segregation behavior from all our other strains. They give rise on streaking to a majority of bio- colonies and a minority of highly sectored bio variable colonies. These bio variable colonies in turn give rise on further restreaking to a majority of bio- 
TABLE 7

Denattr of Various dbio's: DNA Mass of These Particles Relative to That of $\lambda^{\prime \prime}$

\begin{tabular}{|c|c|c|c|c|c|c|c|}
\hline Bio strain & $\begin{array}{l}\text { Phage } \\
\text { end point }\end{array}$ & $\begin{array}{l}\text { Bacterial } \\
\text { end point }\end{array}$ & $\begin{array}{l}\text { Position of } \\
\lambda \text { maxima } \\
\text { (tube No.) }\end{array}$ & $\begin{array}{l}\text { Position of } \\
\lambda \text { cb2 maxima } \\
\text { (tube No.) }\end{array}$ & $\begin{array}{l}\text { Position of } \lambda \text { bic } \\
\text { Transduction }\end{array}$ & Plaque & $\begin{array}{l}\text { DNA mass } \\
\text { relative to } \\
\lambda \mathrm{s}(=1.00)\end{array}$ \\
\hline M66-1 & $\lambda \mathrm{pb}$ & $18 / 19$ & 12 & 21 & 7 & 8 & 1.06 \\
\hline$M 108-1$ & $\lambda p b$ & $18 / 19$ & 9 & 19 & 9 & 9 & 1.00 \\
\hline M7-20 & $\lambda \mathrm{pb}$ & $23 / 18$ & 11 & 22 & 11 & 11 & 1.00 \\
\hline ME5-3 & $\mathrm{R} / \mathrm{A}$ & $23 / 18$ & 10 & 20 & 20 & $\cdots$ & 0.87 \\
\hline M38-ij & $\mathbf{P}_{72} / \mathbf{P}_{3.116}$ & $18 / 19$ & 14 & 27 & 31 & - & 0.81 \\
\hline M37-1 & Within $c_{I}$ & $0,4,24 / 2,17$ & 4 & 14 & 17 & - & 0.82 \\
\hline M40-3 & Within $c_{I}$ & $2,17 / 12$ & 42 & .59 & 64 & $\ldots-$ & 0.82 \\
\hline$M I+2-2$ & Within $c_{I}$ & $3 / 23$ & 42 & 59 & 52 & $\cdots$ & 0.92 \\
\hline M29-6 & Within $c_{I}$ & $18 / 19$ & 14 & 24 & 17 & -- & 0.96 \\
\hline M $3-29$ & $N / i^{\lambda}, c_{4 i}$ & Beyond 19 & 42 & 59 & 20 & $-\ldots$ & 1.15 \\
\hline
\end{tabular}

a The density of 10 different $\lambda$ bio particles relative to that of $\lambda$ and $\lambda c b 2$ was determined by placing the three phage types together in a $\mathrm{CsCl}$ density gradient. $\lambda$ cb2 was added to HFT $\lambda d b$ lysates, which contain $\lambda$ and the transducing particles; both $\lambda_{-I_{-71}}$ and $\lambda$ cb2 were added to HFT $\lambda$ pb lysates made lytically from a single plaque. Transducing activity was assayed on bio 0 , except in one experiment. (with phage types M40-3, M42-2, and M3-29) where bio-19 and bio-3 were also hosts. Turbid and elear plaques were assayed on $\mathrm{C} 600$; turbid plaques in $\lambda$ pb lysates were from $\lambda$ pb particles. Transducing and turbid plaque maxima for $\lambda$ pb lysates are listed by tube number; $\lambda$ and $\lambda c b 2$ maxima are listed in the table too. The DNA content of the $\lambda \mathrm{cb} 2$ phage is $86.6 \%$ that of $\lambda$. The density of $\mathrm{c}_{171}$ is indistinguishable from $\lambda$ 's. The mass difference between $\lambda$ bio and $\lambda$ was calculated according to the method described in Kayajanian and Campbell (1966).

TABLE 8

Proportion of Heteroghente Clones in LFT and HFt Biotin Transduction

\begin{tabular}{|c|c|c|c|c|}
\hline Experiment & Induced strain & Nature of lysate & $\begin{array}{l}\text { Number of biotin } \\
\text { transduced } \\
\text { clones analyzed }\end{array}$ & $\begin{array}{l}\text { Percentage of hetero- } \\
\text { genotic clones among } \\
\text { transductants on bio }-0\end{array}$ \\
\hline 1 & $\mathrm{C} 600(\lambda)$ & LFT & 420 & 17.6 \\
\hline \multirow[t]{3}{*}{2} & $\mathrm{C} 600(\lambda)$ & $\mathrm{LFT}^{a}$ & 52 & 19.2 \\
\hline & bio $-0(\lambda d b M 39-2)(\lambda)$ & $\mathrm{HFT}^{a}$ & 18 & 66.7 \\
\hline & bio-0 $(\lambda$ pbM72-3) $(\lambda)$ & $\mathrm{HFT}^{2}$ & 16 & $62 . \overline{3}$ \\
\hline 3 & bio $^{-0}(\lambda \mathrm{db} 20-5)(\lambda)$ & HFT & 15 & $60^{\%}$ \\
\hline 4 & bio $^{-0}(\lambda d b 30-2)(\lambda)$ & HFT & 12 & $75 \%$ \\
\hline
\end{tabular}

a Transduction for the three lysates were done on the same sample of cells with the same multiplicity of infection of "helper" phage.

colonies and a minority of bio variable colonies. The bio- colonies do not show marker rescue of sus markers, while the bio variable clones do. Rare bio $^{+}$colonies which appear do not segregate and do not give marker rescue of any sus markers.

When grown in broth, the number of cells giving rise to bio variable colonies increases, but the proportion of these cells decreases significantly. Double $\left(\lambda d b c_{I}\right)(\lambda)$ lysogens as well as single lysogens of other $\lambda d b$ do not exhibit any marked change in the proportion of biot to bio- cells during growth (Table 9).
The visual appearance of pronounced sectoring on our segregation medium may be the result of fast conversion of bio $^{+}$cells to bio ${ }^{-}$ cells, or slower conversion coupled with a killing of $\mathrm{bio}^{+}$cells, or fast conversion coupled with killing of $\mathrm{bio}^{+}$cells. (This slower conversion might be at the rate at which other single lysogens segregated biocells. ) If the second or third explanation were correct, then there should be a greater fraction of dead cells in the fast segregating $\left(\lambda \mathrm{db}_{\mathrm{cI}}\right)$ than in the slow segregating $(\lambda \mathrm{db})$ cultures. Dead $E$. coli take up methylene 
TABLE 9

Fraction of bio- Celles in bio Variable Colonies

\begin{tabular}{|c|c|c|c|c|}
\hline \multirow[t]{2}{*}{ Strain } & \multirow[t]{2}{*}{$\lambda \mathrm{db}$ phage end point } & \multirow{2}{*}{$\begin{array}{l}\text { Fraction of bio }{ }^{-} \text {cells } \\
\text { in a bio variable } \\
\text { clone at time }=0\end{array}$} & \multicolumn{2}{|c|}{$\begin{array}{l}\text { Fraction of bio cells in a bio } \\
\text { variable culture after } n \\
\text { generations of growth }\end{array}$} \\
\hline & & & Fraction & $(n)$ \\
\hline $\mathrm{bio}^{-0}(\lambda \mathrm{cb} \mathrm{M} 29-6)$ & Within $c_{I}$ & $81 / 123=66 \%$ & $587 / 620=94.7 \%$ & 6.8 \\
\hline bio-0 $^{-0}(\lambda \mathrm{db} \mathrm{M} 30-7)$ & Within $c_{\text {I }}$ & $145 / 175=83 \%$ & $249 / 251=99.2 \%$ & 19.6 \\
\hline bio $-0(\lambda d b$ M37-1) & Within $c_{1}$ & $219 / 259=85 \%$ & $955 / 959=99.6 \%$ & 21.0 \\
\hline $\mathrm{bio}^{-0}(\lambda \mathrm{db} \mathrm{M} 38-1)$ & Within $\mathrm{c}_{\mathrm{I}}$ & $1132 / 1256=90 \%$ & & \\
\hline $\mathrm{bio}^{-0}(\lambda \mathrm{db} \mathrm{M} 40-3)$ & Within $c_{\mathrm{I}}$ & $207 / 256=81 \%$ & $565 / 601=94.0 \%$ & 6.1 \\
\hline bio-0 (Adb M42-2) & Within cI & $303 / 340=89 \%$ & $888 / 917=97.3 \%$ & 20.5 \\
\hline bio-0 $^{-0}(\mathrm{db} \mathrm{M} 30-7)(\lambda)$ & Within $c_{\mathrm{I}}$ & $10 / 295=3.4 \%$ & $4 / 77=5.2 \%$ & 18.0 \\
\hline bio $^{-0}(\lambda \mathrm{db}$ M37-1) $(\lambda)$ & Within $\mathrm{c}_{\mathrm{I}}$ & $11 / 580=1.9 \%$ & $1 / 33=3.0 \%$ & 15.9 \\
\hline bio-0 ( $(\lambda \mathrm{db}$ M55-3) & Between $\mathrm{R}$ and $\mathrm{A}$ & $1 / 39=2.6 \%$ & $10 / 202=5.0 \%$ & 23.2 \\
\hline $\mathrm{bio}^{-0}(\lambda \mathrm{db} \mathrm{M} 29-7)$ & Between $\mathrm{O}$ and $\mathrm{P}$ & $2 / 309=0.6 \%$ & $1 / 88=1.1 \%$ & 14.8 \\
\hline bio $^{-0}(\lambda \mathrm{db}$ M3-29) & Between $\mathrm{N}$ and $\mathrm{c}_{\mathrm{I}}$ & $2 / 89=2.2 \%$ & $16 / 252=6.3 \%$ & 22.8 \\
\hline Reconstruction bio $-\mathrm{O}(\lambda \mathrm{db}$ & - & $32 / 72=44.4 \%$ & $44 / 89=49.4 \%$ & 21.6 \\
\hline
\end{tabular}

a Broth tubes are inoculated with isolated bio or biov colonies from freshly streaked plates. The cultures are diluted into warmed broth while growing at $37^{\circ}$. Initially, during the course of growth, and after $n$ generations of growth, samples of the culture are assayed for the proportion of bio $^{+}$and/or bio colonies to bio ${ }^{-}$colonies on our segregation medium.

blue which stains structures inside the cell; live $E$. coli exclude the dye. By this test, cultures of the $\lambda \mathrm{db}_{\mathrm{cI}}$ single lysogens have a higher proportion of dead cells ( $55 \mathrm{dead} / 607$ total $=9.1 \%$ ) than other $\lambda \mathrm{db}$ lysogens or bio $^{-} \mathrm{O}(\lambda)$ control cultures $(21 / 574=3.7 \%)$. Since the colonies arising from bio- $\left(\lambda \mathrm{db}_{\mathrm{cI}}\right)$ lysogens contain at least two classes of cells, one of which is slower dying bio-, the proportion of dead cells arising from the other classes may be higher than the figure quoted above. So part of the appearance of fast segregation in a growing culture of bio $^{-}$ $\left(\lambda \mathrm{db}_{\mathrm{cI}}\right)$ lysogens is the result of killing of $\lambda d \mathrm{~b}$ lysogens.

\section{Position of Attachment of $\lambda d b$ Genomes}

We have asked, as has Fuerst (1966), whether a $\lambda$ bio genome attaches to the bactcrial chromosome at or near the normal $\lambda$ insertion site. If a $\lambda$ pb attaches at or near the normal attachment site, induction of a $\lambda \mathrm{pb}$ lysogen should result in the formation of LFT particles able to transduce gal markers or other bio markers. In fact, induction of the $\lambda$ pb lysogen bio- $O(\lambda \mathrm{pb} M 72-3)$ results in the production of a lysate with $\mathrm{HF}^{\prime} \mathrm{T}$ bio transducing activity on bio- $\mathrm{O}$, I.FT gal transducing activity on W3805 and LFT bio transducing activity on bio-19. HFT lysates were made from three of the gal transductants; the gal transducing particles in these lysates transduce bio at high frequency. These bio-gal transducing particles were defective as phages, missing a block of phage genes which includes susJ and extends in various lengths through the tail and into the head region of $\lambda$ 's genome. These particles do not transduce bio ${ }_{19}$ - . It is reasonable to conclude, therefore, that the $\lambda \mathrm{pb}$ lysogenized either at the normal attachment site or near it, but not to the right of the bio region.

A number of gal- bio- ( $\lambda \mathrm{dg})(\lambda \mathrm{db})$ double lysogens were constructed to determine where the two genomes will attach to the host chromosome. The gal ${ }^{-}$bio $^{-}(\lambda \mathrm{db})$ single lysogen was made by the low multiplicity transduction of bio $^{-} \mathrm{O}$ with $\lambda \mathrm{db}$ M55 3 (missing phage cistrons $\mathrm{N}$ through $\mathrm{R}$ ). This $\mathrm{gal}^{-}$bio $^{-}(\lambda \mathrm{db})$ lysogen was then transduced at a low multiplicity of infection by $\lambda d g 0_{1-26}$ (missing phage cistrons A through J). Two independent gal transductants capable of segregating gal- subclones, but yielding low titers of plaque forming particles on induction were studied further. We asked whether 
the gal- segregants from the double lysogen were still $\mathrm{bio}^{+}$and whether they retained cistron $\mathrm{P}$ and $\mathrm{B}$ markers (cistron $\mathrm{P}$ is associated with the $\mathrm{gal}^{+}$in $\lambda \mathrm{dg} ; \mathrm{B}$, with the $\mathrm{bio}^{+}$ in $\lambda d b)$. A number of independently arising $\mathrm{gal}^{-}$segregants from each of the double lysogens were tested for the presence of $B$ and $P$ cistrons and the bio ${ }^{+}$phenotype. We also assayed for the presence of $\mathrm{B}$ and $\mathrm{P}$ cistrons and the gal phenotype in bio segregants of these double lysogens. These results are summarized in Table 10.

We have assumed that the formation of $\mathrm{gal}^{-}$segregants results from the lysogenic host chromosome recombining with itself in a region of $\mathrm{gal}^{+}-\mathrm{gal}^{-}$homology, and the subsequent loss of the small excised chromosomal fragment. Any marker between the two gal markers and therefore on this fragment would be lost too and not recoverable from the gal- segregant. The same assumptions apply for the study of bio- segregants. $\mathrm{Gal}^{-}$segregants from double lysogen strain No. 5 have lost the $\mathrm{P}$ cistron, but neither the $\mathrm{B}$ cistron nor the $\mathrm{bio}^{+}$phenotype. $\mathrm{Bio}^{-}$ segregants from strain No. 5 are gal ${ }^{+}$and have lost cistron $\mathrm{B}$ but not $\mathrm{P}$. Gal- segregants from strain No. 14 are bio and have lost both $\mathrm{B}$ and $\mathrm{P}$ markers. Bio ${ }^{-}$segregants from strain No. 14 are gal $^{-}$and have lost cistron $\mathrm{B}$ and $\mathrm{P}$ genes. The only gene order possible for strain No. 5 is

$$
\mathrm{gal}^{-}(\lambda \mathrm{dg})(\lambda \mathrm{db}) \mathrm{bio}^{-}
$$

where the prophages are in their normal orientation. The gene orders possible for strain No. 14 are:

$$
\mathrm{gal}^{-}(\lambda \mathrm{db})(\lambda \mathrm{dg}) \mathrm{bio}^{-}
$$

TABLE 10

Analysis of gal $^{-}$AND bio SEgRegants From

\begin{tabular}{|c|c|c|c|c|c|c|c|}
\hline \multirow{2}{*}{$\begin{array}{l}\text { Strain } \\
\text { No. }\end{array}$} & \multicolumn{4}{|c|}{$\begin{array}{c}\text { Residual genotype of } \mathrm{gal}^{-} \\
\text {segregants }\end{array}$} & \multicolumn{3}{|c|}{$\begin{array}{l}\text { Rcsidual genotypes of } \\
\text { bio }^{-} \text {segregants }\end{array}$} \\
\hline & $\begin{array}{c}\text { Number } \\
\text { examined }\end{array}$ & $\underset{\text { bio }}{\mathrm{B}^{-}} \mathrm{P}^{-}$ & $\underset{\text { bio }^{+}}{\mathrm{B}^{+} \mathrm{P}^{-}}$ & $\underset{\text { bio }}{\mathrm{B}^{+} \mathrm{P}^{-}}$ & $\begin{array}{c}\text { Number } \\
\text { examined }\end{array}$ & $\mathrm{Bal}^{-}$ & $\underset{\mathrm{gal}^{+}}{\mathrm{B}^{-} \mathrm{P}^{+}}$ \\
\hline 5 & 15 & 1 & 12 & 2 & 2 & 0 & 2 \\
\hline 14 & 7 & $6^{n}$ & 1 & 0 & 6 & 5 & 1 \\
\hline
\end{tabular}
Two gal- bio- $(\lambda \mathrm{db})(\lambda \mathrm{dg})$ Double Lysogens

"A sister clone of one of these segregants was $\mathrm{B}^{\prime} \mathrm{P}^{\mid}$bio. and

$$
\operatorname{gal}^{-}(\lambda \mathrm{db}) \mathrm{bio}^{-}(\lambda \mathrm{dg})
$$

where the prophages are in their normal orientation. So, the $\lambda d b$ genome resides between the gal and bio markers of the $E$. coli host, and probably was inserted at the $\lambda$ attachment site or in a region of homology with the host genome.

A subclone was isolated from strain No. 14 which would not give marker rescue for sus $\mathrm{B}$ or sus P markers, but still segregated galand bio- daughter cells. For this segregant to arise from strain No. 14, the prophage order in that double lysogen would have to be

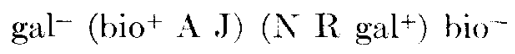

and the subclone from it is probably

$$
\mathrm{gal}^{-}\left(\mathrm{bio}^{+} \mathrm{gal}^{+}\right) \mathrm{bio}^{-} \text {. }
$$

In strains 5 and 14 both $\lambda d g$ and $\lambda d b$ genomes reside between the gal and bio markers of the host chromosome. The presumptive $\mathrm{gal}^{-}\left(\mathrm{bio}^{+} \mathrm{gal}^{+}\right) \mathrm{bio}^{-}$strain was easily lysogenized by phage $\lambda$, and the $(\lambda)$ $(\lambda \mathrm{dbg})$ double lysogen produced an HFT lysate where gal and bio transducing activity were associated with particles of the same low density. Joint transduction frequencies were no less than one-third of the individual transduction frequencies. The DNA content of the $\lambda d b g$ genome is less than the DNA mass of the $\lambda \mathrm{db}$ by about as much as the $\lambda d g$ 's is less than $\lambda$ 's (Kayajanian, unpublished results).

\section{DISCUSSION}

$\lambda$ bio transducing particles derived from an HFT lysate are identical in their content of phage markers and form a Gaussian distribution with a slight tail in a $\mathrm{CsCl}$ density gradient. HFT lysates are developed from independent transductants made from an LFT lysate. $\lambda$ bio particles derived from HFT lysates may and generally do differ from one lysate to another in the content of phage and bacterial markers and in their density. As in the case of $\lambda \mathrm{dg}$, the gene content in $\lambda$ bin genomes represents a contiguous stretch of hereditary material lifted from the lysogenic bacterial chromosome. In general, the denser 
a $\lambda$ bio particle is, the larger its phage genome and/or its bacterial component (Tables 5 and 7 ).

The variability in end points of $\lambda \mathrm{db}$ genomes suggests an independent origin for at least those $\lambda \mathrm{db}$ genomes in LFT lysates that are capable of lysogenizing their bio- hosts. The difference in the ability of LFT and HFT lysates to transduce by lysogeny, rather than just transducing, suggests a difference between $\lambda$ bio particles in an LFT lysate and in all the HFT lysates so far studied. It is possible, therefore, that a significant fraction of biotin transducing particles in LFT lysates may be structurally very different from those which we describe in HFT lysates and may be unable to transduce by lysogeny as a result of these structural differences. These structural differences may be, among other things, the absence of $\lambda$ 's cohesive ends. The variability that we observe in the end points of $\lambda d b$ genomes may not be as great as really exists for another reason. Some of the $\lambda \mathrm{db}$ genomes capable of being maintained as reasonably stable lysogens in the presence of $\lambda$ as $(\lambda)(\lambda \mathrm{db})$ lysogens (which give rise to HFT lysates) may be quite unable to be stably maintained as single $(\lambda d b)$ lysogens. Some $\lambda d b$ genomes may not be stable even as $(\lambda)(\lambda d b)$ lysogens. We were rather surprised when none of eleven $\lambda \mathrm{db}$ genomes having phage end points between cistrons $\mathrm{N}$ and $\mathrm{O}$ were broken between $c_{I}$ and $c_{I I}$, but six were broken within $c_{I}$, for we suspected the $c_{r}$ cistron to be smaller than the $c_{Y}$ to $c_{I I}$ intercistronic distance.

All of our $\lambda \mathrm{db}$ genomes contain the phage markers from the $J$ through A cistrons, though they need not contain cistron $R$ markers. Symmetrically, all the $\lambda d g$ genomes we have encountered (Campbell, 1959, 1962; Kayajanian and Campbell, 1966) contain the phage markers from the $\mathrm{N}$ through $R$ cistrons, though they do not necessarily contain cistron A markers. In the absence of actually performing specific assays for the presence of the vegetative single-stranded ends of $\lambda$ (located between $\mathrm{R}$ and $\mathrm{A}$ ) in all $\lambda d \mathrm{db}$ and $\lambda d g$ particles in HFT lysates, we would like to argue that the method of selection and the measurable genetic end points of $\lambda d b$ and $\lambda d g$ genomes themselves support the presence of $\lambda$ 's single-stranded ends in $\lambda d b s$ missing cistron $\mathrm{R}$ markers and $\lambda$ dg's missing cistron $\mathrm{A}$ markers. Despite the fact that $\lambda d g$ defective lysogens are characterized by the presence of $\lambda$ immunity and the absence of plaqueforming ability, these genomes always contain the unselected markers in cistrons $O$ through R. Similarly, $\lambda \mathrm{db}$ defective lysogens are characterized by the presence of a $\mathrm{J}$ cistron marker and absence of plaqueforming ability, but always contain the unselected markers from cistrons A through $J$. In view of the role in circularization and, thercfore, in lysogenization attributed to the single-stranded ends of $\lambda$, we consider the data above a strong indication that all $\lambda d g$ and $\lambda d b$ genomes capable of forming defective lysogens do contain the vegetative ends of $\lambda$.

Assuming this, then $\lambda \mathrm{dg}_{1-26}$ (missing $\mathrm{A}$ through $J$ ) and $\lambda \mathrm{db}$ M55-3 (missing $\mathrm{N}$ through $R$ ) both contain the vegetative ends of phage $\lambda$. Both also contain an insertion region involved in the recombinational act in lysogenization. The $\lambda d b g$ prophage recombinant between these two, carrying gal and bio in place of both phage arms of $\lambda$, should contain only the insertion and vegetative regions that are of phage origin. The ability of $\lambda d \mathrm{dbg}$ to undergo a lysogenic cycle with $\lambda$ 's help suggests that the structural requirement for undergoing such a circuit are satisfied by the presence of the prophage and vegetative ends of $\lambda$.

Defective lysogens of the six $\lambda d b$ genomes whose phage end points fall within the $\lambda$ immunity region give rise to highly sectored colonies on our segregation medium. Lysogens of more defective and less defective $\lambda \mathrm{db}$ genomes do not give this appearance. Neither do $(\lambda)\left(\lambda \mathrm{db}_{\mathrm{eI}}\right)$ double lysogens. We suppose that bacterial control maintains the more defective $\lambda d b s$ as prophages. It seems reasonable to assume that the function of part of the $\lambda$ phage genome located between $\mathrm{c}_{\mathrm{I}}$ and the $\mathrm{O}$ cistron is responsible for the altered phenotype of the $\left(\lambda \mathrm{db}_{\mathrm{cI}}\right)$ lysogens. Lysogens of less complete $\lambda d b$ genomes segregate more slowly; so these genomes would not have the wherewithal to manifest a fast segregation phenotype. Lysogens of more complete $\lambda \mathrm{db}$ genomes would manage 
to control the expression of the phenotype. We note that all the $\lambda d b$ genomes more complete than $\left(\lambda d b_{c I}\right)$ contain an intact immunity region which is recognized as such a control region.

The growth of bio- $\left(\lambda \mathrm{db}_{\mathrm{eI}}\right)$ cells to form highly sectored colonies is the result, at least, of segregation of bio- $^{-}$subclones from $\mathrm{pa}^{-}$ rental cells. That practically every colony arising from bio- $\left(\lambda d b_{\text {eI }}\right)$ lysogens is very highly sectored indicates that independent segregational events occur frequently-more frequently, than in other bio ${ }^{-}(\lambda \mathrm{db})$ or $\mathrm{gal}^{-}$ $(\lambda d g)$ lysogens. This greater rate of conversion of lysogenic to nonlysogenic cells may by itself explain the very large fraction of bio- cells in a sectored colony and the pronounced increase in the proportion of biocells in a culture starting from a bio ${ }^{-}\left(\lambda \mathrm{db}_{\mathrm{cI}}\right)$ colony. Segregation alone will account for highly sectored colonies, whereas differential growth rates will not.

What about the killing? It may be an irrelevance to our other observations or a byproduct of segregation which expresses itself at least one generation after the segregational event. We have imagined the segregational event to be the excision of the $\lambda \mathrm{db}_{\mathbf{e}}$ genome from the lysogenic host chromosome. If the effect of the excision were to damage the host chromosome (in a polynucleate cell) so it would not function, then all the bio- segregants should be killed, and we would not see segregation in bio- $\left(\lambda d b_{e I}\right)$ colonies. If the killing function were physiological, expressed some time after the segregational event by a nonreplicating, nonrepressible excision fragment, then the daughter cell that would die would be the one containing the fragment. Sometimes this cell would be $\mathrm{bio}^{+}$, and sometimes bioO-P killing (Packman and Sly, 1968), resulting from the inability of phage genomes to control $\mathrm{O}$ and $\mathrm{P}$ function could account for our dead cells. The absence of an $N$ gene in our $\lambda d b_{e r}$ genome could delay the killing for more than a cell division so we would be able to see segregation.

\section{ACKNOWLEIGMENT}

The author is grateful to the Drs. Campbell for looking after him.

\section{REFERENCES}

Adler, J., and Templeton, B. (1963). The amount of galactose genetic material in $\lambda \mathrm{dg}$ bacteriophage with different densities. J. Mol. Biol. 7,710720 .

Campbell, A. (1959). Ordering of genetie sites in bacteriophage $\lambda$ by the use of galactose-transducing defective phages. Virology 9, 293-305.

Campbell, A. (1962). Jistribution of genetic types of transducing $\lambda$ phages. Genetics 48, 409-421.

del Campillo-Campbell, A., Kayajanlan, $\mathrm{G}$., Campaell, A., and Adhya, S. (1967). Biotin mutants of Escherichia coli K12. J. Bacteriol. 94, 2065-2066.

Fuerst, C. R. (1966). Defective biotin-transduc. ing mutants of bacteriophage Lambda. Virol. ogy 30, 581-583.

Kayajanian, G., and Campbell, A. (1966). The relationship between heritable physical and genetic properties of selected $\mathrm{gal}^{-}$and $\mathrm{gal}^{+}$. transducing $\lambda \mathrm{dg}$. Virology 30, 482-492.

Morse, M. L., Lederberg, E. M., and LeberBERG, J. (1956a). Transduction in Escherichia coli K12. Genetics 41, 142-156.

Morse, M. L., Lederberg, E. M., and LederBERG, J. (1956b). Transductional heterogenotes in Escherichia coli. Genetics 41, 758-779.

Packman, S., and Sly, W. S. (1968). Constitutive $\lambda$ DNA replication by $\lambda c_{1 i}$, a regulatory mutant related to virulence. Virology $\mathbf{3 4}, 778-789$.

Rothman, J. (1965). Transduction studies on the relation between prophage and host chromosome. .J. Mol. Biol. 12, 892-912.

SMrTH, H. O. (1968). Defective phage formation by lysogens of integration deficient phage P22 mutants. Virology 34, 203-223.

Waldace, B., and PitTard, J. (1967). Genetic and biochemical analysis of the isoenzymes concerned in the first reaction of aromatic biosynthesis in Escherichia coli. I. Bacteriol. $93,237 \cdots 244$. 